\title{
In Situ Synthesis of Reduced Graphene Oxide-Reinforced Silicone-Acrylate Resin Composite Films Applied in Erosion Resistance
}

\author{
Yang Cao, ${ }^{1}$ Xiaoyong Tian, ${ }^{1}$ Yan Wang, ${ }^{1}$ Youyi Sun, ${ }^{1}$ Hailin Yu, \\ Dian-sen $\mathrm{Li}^{2}$, and Yaqing Liu ${ }^{1}$ \\ ${ }^{1}$ Research Center for Engineering Technology of Polymeric Composites of Shanxi Province, North University of China, \\ Taiyuan 030051, China \\ ${ }^{2}$ Key Laboratory of Bio-Inspired Smart Interfacial Science and Technology of Ministry of Education, \\ Beijing Key Laboratory of Bio-Inspired Energy Materials and Devices, School of Chemistry and Environment, \\ Beijing University of Aeronautics and Astronautics, Beijing 100191, China
}

Correspondence should be addressed to Youyi Sun; syyi@pku.edu.cn and Yaqing Liu; lyqzgz2010@163.com

Received 24 May 2015; Revised 19 August 2015; Accepted 24 August 2015

Academic Editor: Konstantinos I. Tserpes

Copyright (C) 2015 Yang Cao et al. This is an open access article distributed under the Creative Commons Attribution License, which permits unrestricted use, distribution, and reproduction in any medium, provided the original work is properly cited.

The reduced graphene oxide reinforced silicone-acrylate resin composite films (rGO/SAR composite films) were prepared by in situ synthesis method. The structure of rGO/SAR composite films was characterized by Raman spectrum, atomic force microscope, scanning electron microscopy, and thermogravimetric analyzer. The results showed that the rGO were uniformly dispersed in silicone-acrylate resin matrix. Furthermore, the effect of rGO loading on mechanical properties of composite films was investigated by bulge test. A significant enhancement (ca. 290\% and 320\%) in Young's modulus and yield stress was obtained by adding the rGO to silicone-acrylate resin. At the same time, the adhesive energy between the composite films and metal substrate was also improved to be about $200 \%$. Moreover, the erosion resistance of the composite films was also investigated as function of rGO loading. The rGO had great effect on the erosion resistance of the composite films, in which the $R_{\text {corr }}$ (ca. $0.8 \mathrm{~mm} /$ year) of composite film was far lower than that $(28.7 \mathrm{~mm} /$ year $)$ of pure silicone-acrylate resin film. Thus, this approach provides a novel route to investigate mechanical stability of polymer composite films and improve erosion resistance of polymer coating, which are very important to be used in mechanical-corrosion coupling environments.

\section{Introduction}

An intense effort is underway to find coatings that inhibit the process of metal corrosion, a problem costing US industries more than $\$ 200$ billion annually [1]. Corrosion can be inhibited or controlled by introducing a stable protective layer made of inert metals [2], conductive polymers [3], or even thiol-based monolayers [4] between a metal and a corrosive environment. In particular, polymeric coating has attracted considerable interest due to lightweight, low-cost, and being fabricated easily and inexpensively by employing cost-effective techniques, for instance, inkjet and spray coating [5-7]. Most of these works have focused more on erosion resistance of polymeric coating. However, the application environment of corrosion-resistant polymeric coating was multienvironmental fields of corrosion, mechanics, and thermo in practical engineering [8]. In addition to this, the erosion resistance of polymeric coatings was usually closely related to their mechanical properties such as Young's modulus, ultimate tensile strength, and adhesive energy. For example, when the coating barrier was mechanically damaged and the corrosive species penetrate the metal surface, the corrosion process could not be avoided $[8,9]$. So, the study of mechanical behavior was very important to design and practical application of corrosion-resistant polymer thin film. However, there were few works reporting on the 
mechanical behavior of corrosion-resistant polymer thin film because these mechanical properties (i.e., elastic modulus, yield strength, and adhesive energy) of corrosion-resistant polymeric coatings were difficult to be measured by the conventional tensile test [10]. Therefore, it is of great necessity to find a new method to investigate the mechanical properties of corrosion-resistant polymer thin film with metal substrate. Silicone-acrylate resin was a common polymeric coating that inhibited the process of metal corrosion [11]. And graphene was the strongest material and effective corrosion-inhibiting materials known to man [12]. So, graphene nanosheets (GNS) reinforced silicone-acrylate resin thin film is expected to be a good kind of anticorrosive material with high performance. To the best of our knowledge, the erosion resistance of polymer composite thin film based on graphene materials was rarely reported.

In this study, the GNS reinforced silicone-acrylate resin composite thin film was prepared by the in situ synthesis method. Furthermore, their mechanical properties (i.e., elastic modulus, yield stress, and adhesive energy) were characterized by the modified bulge test. Moreover, erosion resistance of GNS-based silicone-acrylate resin coating was also investigated by electrochemical measurements. These results are very important to improve the mechanical properties and erosion resistance of polymer coating, which is used as a stable protective layer applied in metal corrosion.

\section{Experimental}

2.1. Materials. Nature graphite flakes (325 mesh, 99.8\%), sodium hydroxide emulsion (37.0 wt\%), and other chemicals and reagents used in this work are of analytical grade. Deionized water was used for preparation, dilution, and analytical purpose.

\subsection{Preparation of $r G O /$ Silicone-Acrylate Resin Composite} Film. rGO was prepared from natural graphite by our own group, and the preparation process was shown in previous work [13]. An appropriate amount of rGO aqueous solution $(2.5 \mathrm{mg} / \mathrm{mL})$, calculated by $0,0.27,1.1$, and $1.93 \mathrm{wt} \%$ with respect to silicone-acrylate resin, was introduced into the solution containing silicone-acrylate and then further mixed under magnetic stirring for $1 \mathrm{~h}$ at room temperature. The resultant mixture was coated onto a clean $\mathrm{Zn}$ plate and then cured at $80^{\circ} \mathrm{C}$ for $2 \mathrm{~h}$.

2.3. Characterization. Raman spectrum was collected on a Jobin-Yvon LabRam HR800 Raman spectroscope equipped with a $514.5 \mathrm{~nm}$ laser source.

AFM images were taken of rGO by a NTMDT NTEGRA SPM instrument with NSG03 noncontact "golden" cantilevers.

The morphology of samples was observed by scanning electron microscopy (SEM) (Su-1500, HITACHI, Japan) with an accelerating voltage of $20 \mathrm{kV}$.

Thermogravimetric analysis (TGA) was carried out using a TA Q600 instrument in a temperature range from 20 to $600^{\circ} \mathrm{C}$ with a heating rate of $10^{\circ} \mathrm{C} \mathrm{min}^{-1}$ in air.

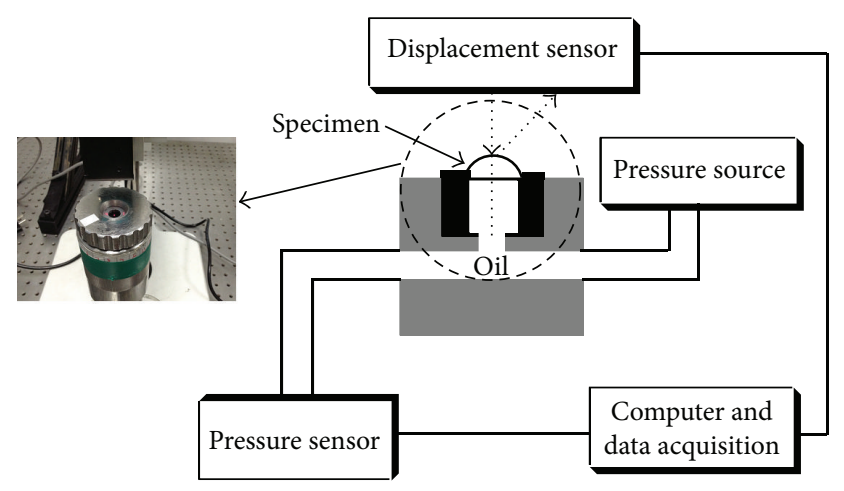

SCHEME 1: The bulge test setup used in present work.

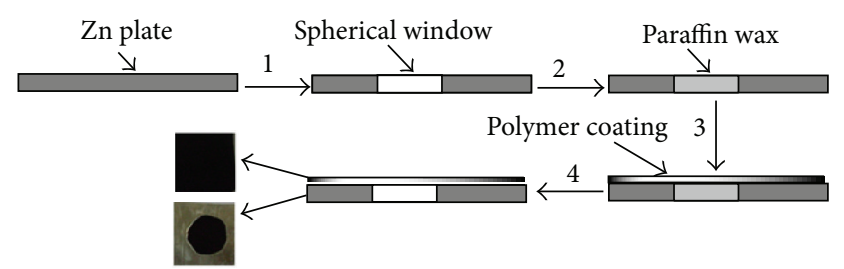

Scheme 2: Schematic illustration for the stepwise preparation of the sample used in bulge test.

\subsection{Mechanics Measurement by Bulge Test}

2.4.1. Bulge Test System. Mechanical properties of polymeric coating were characterized by the bulge test as shown in Scheme 1 . The system contains a small inner chamber used to control the pressure exerted on the coating and a large outer chamber for ambient control. The pressurizing medium was dry nitrogen and the flow rate was controlled by a mass flow controller. A pressure gauge was installed to the chamber and the pressure signals were transferred to a computer for recording and to a processor controller for regulating a proportional valve to maintain an intended pressure. The Michelson type of interferometer was used to measure the bulging of the coating. The difference between our optical setup and a typical Michelson interferometer was that the optical window used for the chamber acted as the reference mirror. An expander lens was used to expand the interference pattern onto a viewing screen. The interference pattern was then recorded using a digital video recorder with a frame rate of $30 \mathrm{frames} / \mathrm{s}$. The recorded images and the bulge height were then transferred to a computer for analysis.

2.4.2. Preparation of Sample Used in Bulge Test. Preparation of sample used in bulge test was shown in Scheme 2. Firstly, chemical-etching method was used to fabricate spherical window in center of $\mathrm{Zn}$ plate $(2.0 \mathrm{~cm} \times 2.0 \mathrm{~cm})$, in which the diameter of spherical window was about $10.0 \mathrm{~mm}$. Secondly, paraffin wax was filled into spherical window in center of $\mathrm{Zn}$ plate. Thirdly, the rGO/silicone-acrylate resin mixture solution was coated onto surface of $\mathrm{Zn}$ plate with spherical window and cured at $60^{\circ} \mathrm{C}$ for $10.0 \mathrm{~min}$. Finally, the paraffin 
wax was removed by heating at $80^{\circ} \mathrm{C}$ and the $\mathrm{rGO} /$ siliconeacrylate resin composite film with $\mathrm{Zn}$ plate substrate was further cured at $80^{\circ} \mathrm{C}$ for 2 hours.

2.4.3. Theory. The generalized equation for bulge test has been established by Huang et al. [14] following the energyminimization approach and can be expressed as

$$
\begin{aligned}
& P=\frac{4 t}{a^{2}} \sigma_{0} h+\frac{8 t Y}{3 a^{4}} h^{3}, \\
& \frac{P}{h}=\frac{4 t}{a^{2}} \sigma_{0}+\frac{8 t Y}{3 a^{4}} h^{2},
\end{aligned}
$$

where $P$ is the pressure, $\sigma_{0}$ is residual stress, $h$ is bugle height measured at the center of the window, $a$ is the dimension of the window, $t$ is the coating thickness, and $Y$ is the biaxial modulus of the polymer coating and is defined as $E /(1-v)$. $E$ and $v$ are Young's modulus and Poisson ratio (ca. 0.45 ) of polymer coating [15], respectively.

For the small strain case, the yield stress expression can be expressed as [16]

$$
\sigma=\frac{P_{0} a^{2}}{4 h_{0} t}
$$

where $\sigma$ is yield strength, $P_{0}$ is the pressure, and $h_{0}$ is bugle height, which are obtained from the cure of $P$ versus $h$ and correspond to elastic deformation transferred to plastic deformation.

For the elastic strain case, the adhesive energy expressions can be expressed as [17]

$$
\begin{aligned}
G & =\frac{P_{0} h_{0}}{f(v)}\left(\frac{1}{8 \gamma}+\frac{\gamma^{2}\left(1-v^{2}\right)}{2}\right), \\
f(v) & =\sqrt[3]{\frac{3(1-v)}{(7-v)}}
\end{aligned}
$$

where $G$ is the adhesive energy of interface between polymer composite coating and $\mathrm{Zn}$ plate substrate, $P_{0}$ is the pressure, and $h_{0}$ is bugle height, which are obtained from the cure of $P / h$ versus $h^{2}$ and correspond to elastic deformation transferred to plastic deformation, and $v$ is Poisson ratio and is assumed as 0.45 . And then $\gamma=g(v)=0.362$.

\subsection{Corrosion Measurements}

2.5.1. Preparation of Sample Used in Corrosion Measurements. As a typical procedure to prepare samples for corrosion measurements, freshly the $\mathrm{rGO} /$ silicone-acrylate resin mixture solution was coated onto the $\mathrm{Zn}$ plate $(2.0 \mathrm{~cm} \times 2.0 \mathrm{~cm})$ and the $\mathrm{rGO} /$ silicone-acrylate resin composite film dried for $2 \mathrm{~h}$ at $80^{\circ} \mathrm{C}$. The $\mathrm{rGO} /$ silicone-acrylate resin composite film with $\mathrm{Zn}$ plate substrate was then mounted to the working electrode. The other uncoated side and edges of $\mathrm{Zn}$ plate were sealed with super-fast epoxy cement (SPARR).
2.5.2. Electrochemical Measurements. All the electrochemical measurements of corrosion potential and corrosion current were performed on a Volta Lab model 21 Potentiostat/Galvanostat in a standard corrosion test cell equipped with a saturated calomel reference electrode (SCE) and a working electrode, and all experimental data were repeated at least three times. The electrolyte was an aqueous solution containing $3.5 \mathrm{wt} \%$ of sodium chloride. Open circuit potential (OCP) at the equilibrium state of the system was recorded as the corrosion potential $\left[E_{\text {corr }}(\mathrm{V})\right.$ versus SCE]. Corrosion current $\left(I_{\text {corr }}\right)$ is determined by superimposing the straight line along the linear portion of the cathodic or anodic curve and extrapolating it through $E_{\text {corr }}$. Corrosion rate $\left(R_{\text {corr }}, \mathrm{mm} /\right.$ year) is calculated from the following equation [18]:

$$
R_{\text {corr }}(\mathrm{mm} / \text { year })=\frac{\left(3270 \times I_{\text {corr }} \times \mathrm{EW}\right)}{\rho},
$$

where EW is the equivalent weight $(\mathrm{g}), I_{\text {corr }}$ is the corrosion current density $\left(\mu \mathrm{A} / \mathrm{cm}^{2}\right)$, and $\rho$ is the density $\left(\mathrm{g} / \mathrm{cm}^{3}\right)$.

\section{Results and Discussion}

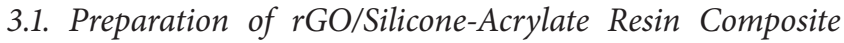
Film. The Raman spectrum of $\mathrm{rGO} /$ silicone-acrylate resin composite film was shown in Figure 1(a). It clearly shows two peaks of $1340.3 \mathrm{~cm}^{-1}$ and $1594.6 \mathrm{~cm}^{-1}$ assigned to $\mathrm{D}$ and $\mathrm{G}$ bands of $\mathrm{rGO}$, and the $I_{\mathrm{D}} / I_{\mathrm{G}}$ intensity ratio is about 1.1 , implying the existence of rGO in the composite film [19]. The rGO/silicone-acrylate resin composite film was further characterized by the atomic force microscopy (AFM) as shown in Figure 1(b). It clearly showed some sheet-like fillers in silicone-acrylate resin matrix, which may be assigned to rGO sheets. At the same time, it clearly showed that the size and thickness of rGO sheets were about $5.5 \mu \mathrm{m}$ and $2.4 \mathrm{~nm}$, respectively. These results confirmed the formation of $\mathrm{rGO} /$ silicone-acrylate resin composite film with good dispersion.

The structure of $\mathrm{rGO} /$ silicone-acrylate resin composite film was investigated by the SEM as shown in Figure 2. The SEM images reveal very different morphologies for rGO/silicone-acrylate resin composite film with various contents of rGO. The smooth layer mainly consists of polymer while the interior ones (bright spots) are due to the rGO phase, which confirms the particles' distribution on the surface. The SEM images also show that the composite films consist of rGO fillers with sheet-like shape for the as-grown film and agglomerated mosaic structures observed for the composite films with rGO content of $1.9 \mathrm{wt} \%$. In addition, the surfaces of all films were smooth, pin hole free, and free of cracks, which was very important to improve the corrosion resistance of coatings. The insets in Figures 2(b)-2(d) display the optical images of the composite films. The surface color of the pure silicone-acrylate resin film that changed from transparent (in inset in Figure 2(a)) to black also demonstrates the doping of rGO in silicone-acrylate resin matrix. In addition to this, the black color was uniform on composite films. These results indicate that the rGO could be uniformly dispersed in silicone-acrylate resin matrix by a simple method. 


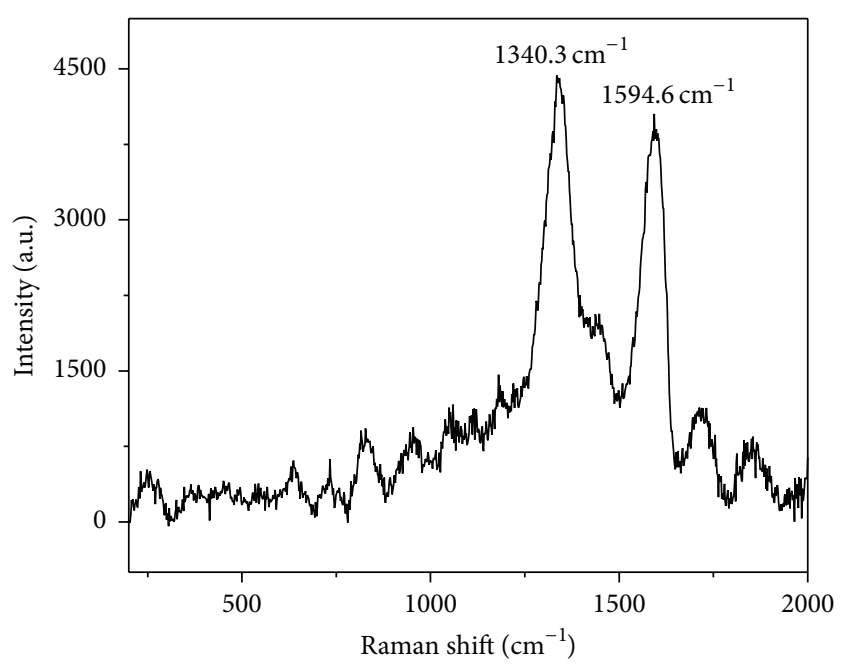

(a)

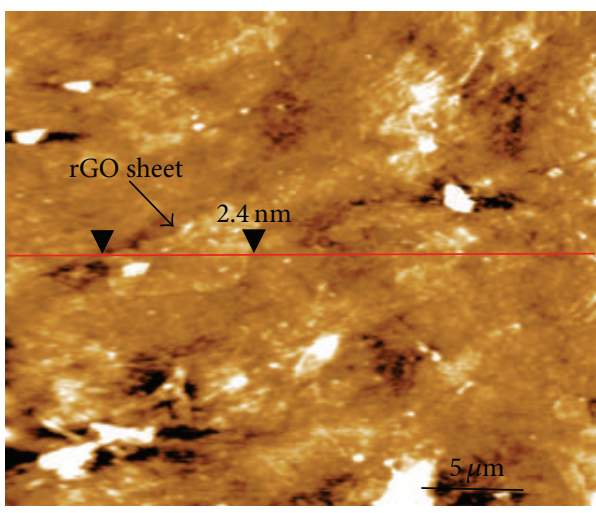

(b)

FIGURE 1: (a) Raman spectrum and (b) AFM of polymer composite film.

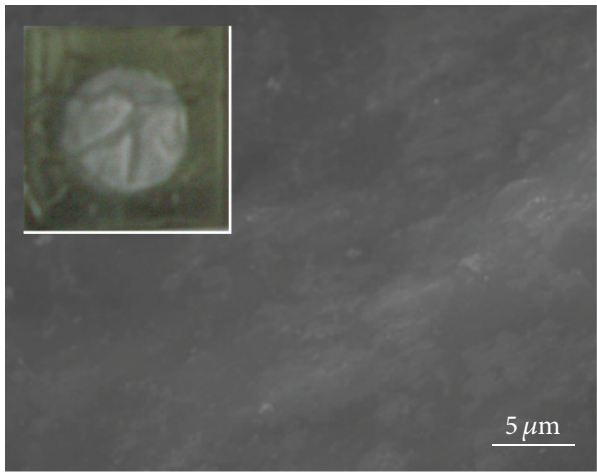

(a)

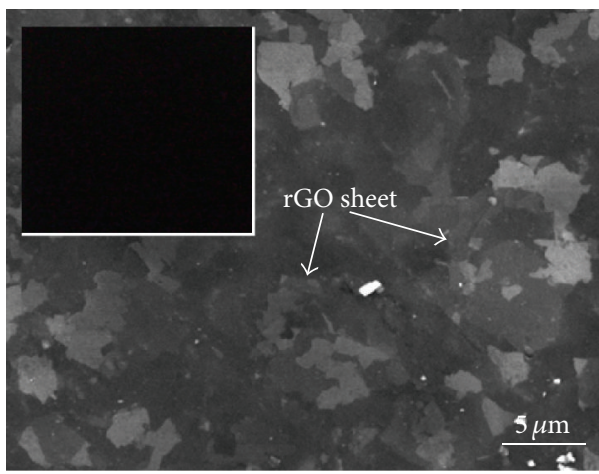

(c)

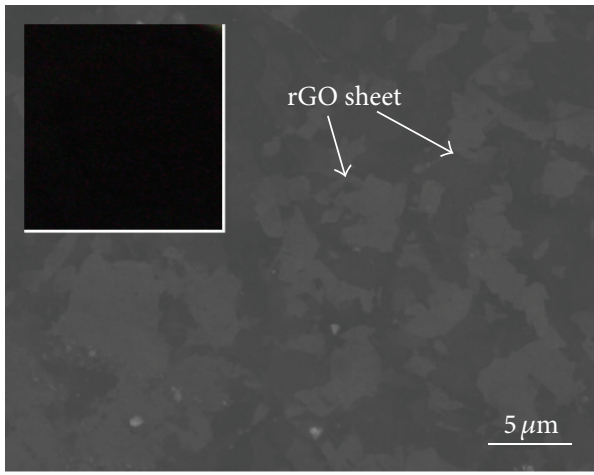

(b)

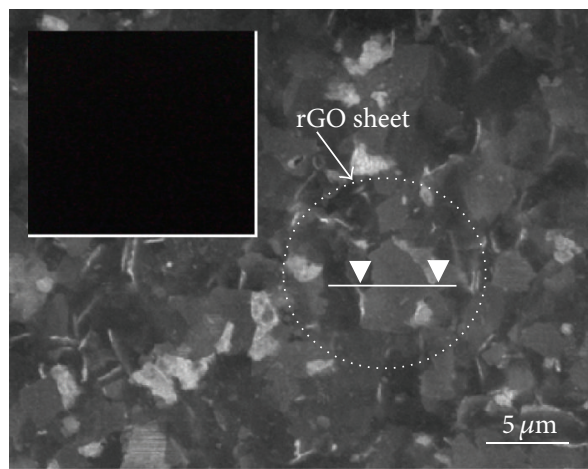

(d)

FIGURE 2: SEM of polymer composite film with various rGO contents of (a) 0 , (b) $0.27 \mathrm{wt} \%$, (c) $1.1 \mathrm{wt} \%$, and (d) $1.93 \mathrm{wt} \%$. The insets show the photographs of polymer composite films.

Figure 3 shows the thermogravimetric (TGA) analysis of $\mathrm{rGO}$ /silicone-acrylate resin composite film. As shown in Figure 3, all the samples have only one decomposition step. The thermal stability of rGO/silicone-acrylate resin composite films was clearly increased, which are determined from the thermal decomposition temperature at weight loss of
$10.0 \mathrm{wt} \%\left(T_{10}\right) \cdot T_{10}$ of composite films increased from $307.0^{\circ} \mathrm{C}$ to $336.0^{\circ} \mathrm{C}$, corresponding to doping content of 0 and $1.93 \mathrm{wt} \%$. It may be due to the interactions between the rubber matrix and the fillers. The NR macromolecules are attached on GO surface, which thus decreased the amplitude of their thermal motions as well as the degradation probability [20]. 


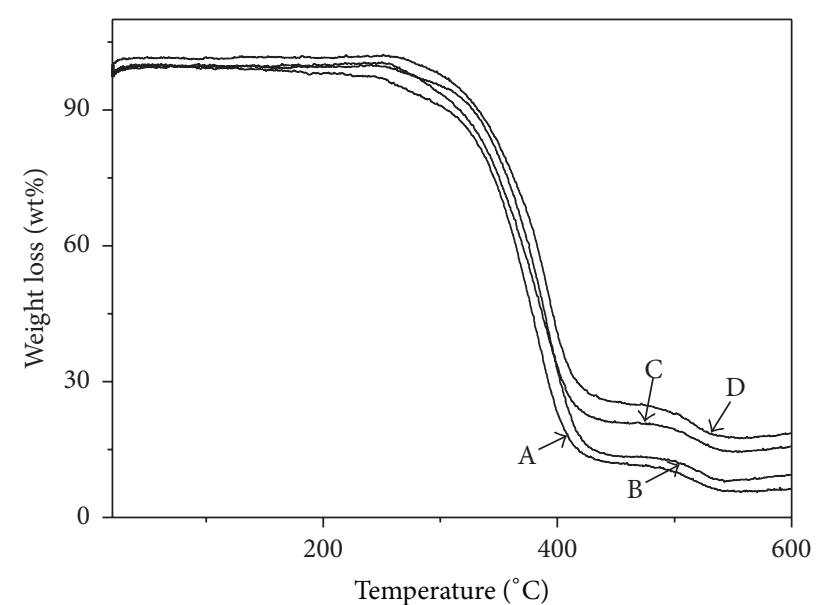

FIGURE 3: TG curves of polymer composite films with various rGO contents of (a) 0 , (b) $0.27 \mathrm{wt} \%$, (c) $1.1 \mathrm{wt} \%$, and (d) $1.93 \mathrm{wt} \%$.

Here, the good dispersion of rGO in silicone-acrylate resin matrix is also responsible for the improvement of $T_{10}$, resulting in formation of more physical cross-linking point between inorganic particles and polymer matrix.

3.2. Mechanical Properties and Erosion Resistance of rGO/ Silicone-Acrylate Resin Composite Film. Figure 4 showed typical pressure versus deflection curves of $\mathrm{rGO} /$ siliconeacrylate resin composite film, which was measured by the bulge test. Regardless of the processing conditions, the mechanical properties of silicone-acrylate resin were altered significantly by the rGO sheets. All composite films showed increased modulus and strength versus neat silicone-acrylate resin film, and the modulus and strength have strong dependence on rGO loading. As shown in Table 1, the strength and moduli are improved rapidly with the increasing rGO content. However, they show a gradual decrease with further addition of rGO. The significant improvements of the strength and moduli are due to the very good exfoliation, high aspect ratio, uniform distribution of rGO in the siliconeacrylate resin matrix, and the hydrogen bonding between rGO and the polymer [21]. These interactions are believed to assist in forming a glassy layer at the filler-rubber interface. During the bulge test, the chains in this glassy layer could be easily reorientated and aligned together by slipping the chains along the filler [22]. After the chains' reorientation, the external stress can be distributed uniformly to avoid stress concentration [21]. When rGO content is more than $1.1 \mathrm{wt} \%$, the strength and moduli start to slightly decrease because of the aggregation of excessive rGO content as shown in Figure 2. In addition, it can be seen that the experimental results coincide with the elastic theory only when the pressure is small. As the pressure increases, the results evidently deviate from that of elastic theory. It indicates that considerable viscoelastic deformation is induced under high stress. It can also be seen that the pressure versus deflection curves of these composite films trended toward that of a thermoplastic deformation at higher pressure comparing to pure silicone-acrylate resin film.

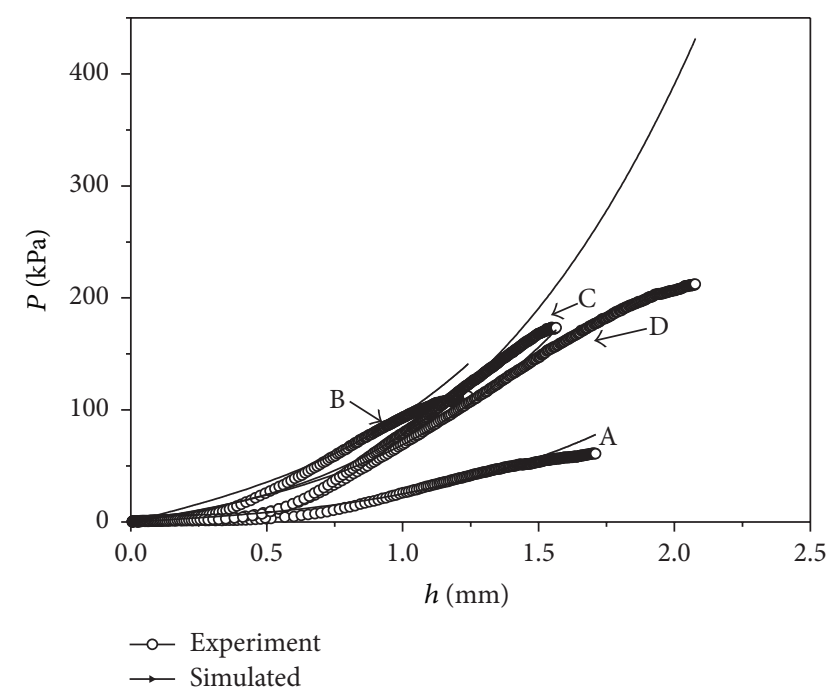

FIgURE 4: The bulge test data of polymer composite films with various rGO contents of (a) 0 , (b) $0.27 \mathrm{wt} \%$, (c) $1.1 \mathrm{wt} \%$, and (d) $1.93 \mathrm{wt} \%$.

Adhesion energy of $\mathrm{rGO} /$ silicone-acrylate resin composite film against the rGO content was calculated by (3) as shown in Table 1, too. The adhesion energy between rGO/ silicone-acrylate resin composite film and $\mathrm{Zn}$ substrate was significantly improved compared with pure silicone-acrylate resin film. It also showed that adhesion energy increased with increase in the rGO content. The average adhesion energy for pure silicone-acrylate resin film was about $5.5 \mathrm{~N} / \mathrm{m}$. The adhesion energy gradually increased to $12.3 \mathrm{~N} / \mathrm{m}$ for the polymer composite films with rGO content of $1.93 \mathrm{wt} \%$, corresponding to an improvement of $224.0 \%$. This indicated that the introduction of rGO into silicone-acrylate resin matrix could effectively improve the interface force between silicone-acrylate resin film and metal substrate. The result was attributed to the fact that the interatomic force between rGO and metal was stronger than the typical van der Waals force between silicone-acrylate resin and metal [22]. The stronger bonding was due to an increase in the electronic density at the interface between the rGO and the metal, although the bonding type was basically van der Waals adhesion [23]. To the best of our knowledge, this has not been explicitly demonstrated elsewhere and therefore requires further study.

The corrosion protection of $\mathrm{Zn}$ plates by $\mathrm{rGO}$ /siliconeacrylate resin composite film was investigated by electrochemical impedance spectroscopy as shown in Figure 5. And then the corrosion potential $\left(E_{\text {corr }}\right)$, corrosion current $\left(I_{\text {corr }}\right)$, and corrosion rate $\left(R_{\text {corr }}\right)$ were listed in Table 2. It clearly showed that the $\mathrm{Zn}$ plates coated with GNS reinforced silicone-acrylate resin composite films all showed lower values of $I_{\text {corr }}$ and $R_{\text {corr }}$ than the pure silicone-acrylate resin film, implying that the $\mathrm{rGO} /$ silicone-acrylate resin composite films were nobler toward electrochemical corrosion relative to the pure silicone-acrylate resin. For example, the $\mathrm{rGO} /$ siliconeacrylate resin composite film $(1.1 \mathrm{wt} \%)$ with $\mathrm{Zn}$ substrate showed a low $I_{\text {corr }}$ value of $0.45 \mu \mathrm{A} / \mathrm{cm}^{2}$ in $3.5 \mathrm{wt} \% \mathrm{NaCl}$, which was about three orders of magnitude lower than the 
TABLE 1: The mechanical properties of the polymer composite film measured by the bulge test.

\begin{tabular}{lccccc}
\hline Loading (wt\%) & Biaxial modulus $(\mathrm{GPa})$ & Young's modulus $(\mathrm{GPa})$ & Residual stress $(\mathrm{MPa})$ & Yielded stress $(\mathrm{MPa})$ & $\mathrm{G}(\mathrm{N} / \mathrm{m})$ \\
\hline 0 & 0.08 & 0.05 & 4.6 & 8.2 & 5.5 \\
0.27 & 0.13 & 0.07 & 10.3 & 14.8 & 6.1 \\
1.10 & 0.25 & 0.14 & 10.5 & 24.1 & 11.4 \\
1.93 & 0.20 & 0.11 & 12.2 & 22.7 & 12.3 \\
\hline
\end{tabular}

TABLE 2: Anticorrosive performance of polymer composite film measured from electrochemical measurements.

\begin{tabular}{lccc}
\hline Loading & $E_{\text {corr }}(\mathrm{mV})$ & $I_{\text {corr }}\left(\mu \mathrm{A} / \mathrm{cm}^{2}\right)$ & $R_{\text {corr }}(\mathrm{mm} /$ year $)$ \\
\hline 0 & -327 & 13.8 & 28.7 \\
$0.27 \%$ & -878 & 6.2 & 4.6 \\
$1.1 \%$ & -585 & 0.45 & 0.8 \\
$1.93 \%$ & -976 & 6.7 & 5.0 \\
\hline
\end{tabular}

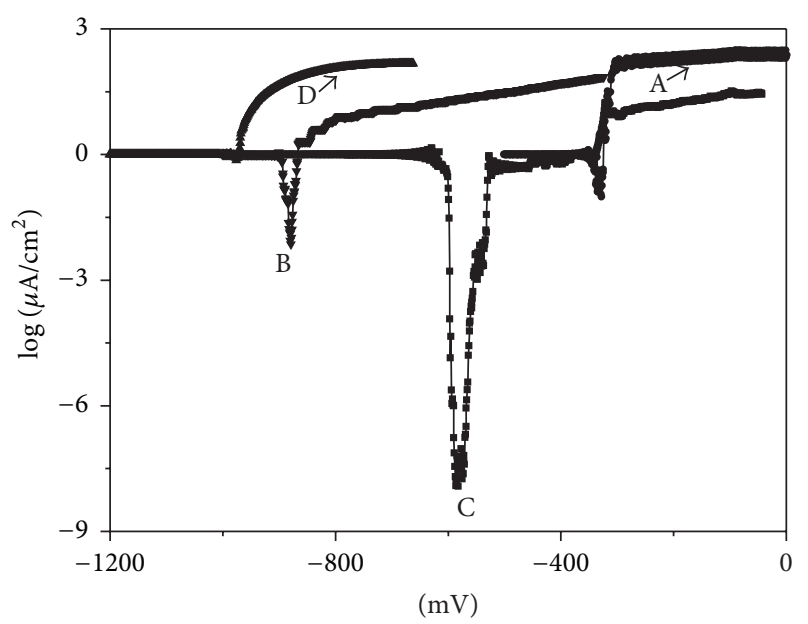

FIGURE 5: The Tafel plots for polymer composite films with various rGO contents of (a) 0 , (b) $0.27 \mathrm{wt} \%$, (c) $1.1 \mathrm{wt} \%$, and (d) $1.93 \mathrm{wt} \%$.

pure silicone-acrylate resin film with $\mathrm{Zn}$ substrate. The corresponding $R_{\text {corr }}$ of $\mathrm{rGO} /$ silicone-acrylate resin composite film (1.1 wt \%) with $\mathrm{Zn}$ substrate was ca. $0.8 \mathrm{~mm} /$ year, which was smaller than that $(28.7 \mathrm{~mm} /$ year $)$ of silicone-acrylate resin film. Although only a small proportion of rGO was incorporated into the silicone-acrylate resin film, high corrosion protection was afforded. By comparison with that of siliconeacrylate resin film in the previous works [11, 24, 25], the corresponding $R_{\text {corr }}$ of $\mathrm{rGO} /$ silicone-acrylate resin composite film was smaller. The good corrosion resistance may be attributed to the following two reasons: (1) silicone-acrylate resin could act as a physical barrier coating and (2) the welldispersed rGO embedded in silicone-acrylate resin matrix could prevent corrosion owing to a relatively higher aspect ratio than clay platelets, which enhances the oxygen barrier property of $\mathrm{rGO} /$ silicone-acrylate resin composite film $[10$, 25].

Figure 6 showed typical SEM images of the corroded surface of uncoated and coated $\mathrm{Zn}$ plates after 6 days of immersion in $3.5 \mathrm{wt} \% \mathrm{NaCl}$ solution. It clearly showed that no distinct cracks or pitting corrosion was observed for all $\mathrm{Zn}$ plates coated with $\mathrm{rGO} /$ silicone-acrylate resin composite thin film compared with the uncoated $\mathrm{Zn}$ specimen (in Figure 6(b)). Additionally, there were no changes in the surface of the coated specimen before and after corrosion (Figures $6(\mathrm{a})$ and $6(\mathrm{c})-6(\mathrm{f})$, resp.). These results indicated that silicone-acrylate resin film was a good kind of protective layer for inhibiting the process of metal corrosion. Surface of the all specimens coated with polymer coating after corrosion was furthermore compared as shown in Figures 6(c)-6(f). It was obvious that there were some holes on surface of $\mathrm{Zn}$ plates coated with pure silicone-acrylate resin and $\mathrm{rGO} /$ siliconeacrylate resin composite film (1.93 wt\%), indicating the presence of local corrosion. Contrarily, there were no holes on surface of $\mathrm{Zn}$ plates coated with $\mathrm{rGO} /$ silicone-acrylate resin composite films $(0.27 \mathrm{wt} \%$ and $1.1 \mathrm{wt} \%)$. Based on the results of the electrochemical tests and corroded surface analysis, the $\mathrm{rGO} /$ silicone-acrylate resin composite films $(0.27 \mathrm{wt} \%$ and $1.1 \mathrm{wt} \%$ ) exhibited better corrosion resistance than other samples. The results were similar to the mechanical properties of polymer composite films as function of rGO content. It is well-known that mechanical properties (such as Young's modulus and hardness) and erosion resistance play important roles in the corrosion behavior of materials: a low mechanical property with high porosity and erosion resistance allows for the penetration of solution, which leads to local corrosion [10]. The $\mathrm{rGO} /$ silicone-acrylate resin composite film (0.7 wt $\%)$ exhibited better mechanical properties and a finer and more dense surface as shown in Table 1 and Figure 2, respectively. In addition to this, $\mathrm{rGO}$ was a good inhibitor and rGO distributed on silicone-acrylate resin matrix could form a good protective layer to act as a barrier to the penetration of solution [26-28]. For these reasons, the rGO/siliconeacrylate resin composite film with good mechanical properties presented better corrosion resistance.

\section{Conclusions}

The rGO/silicone-acrylate resin composite films were prepared by in situ synthesis method and the rGO was well dispersed in the silicone-acrylate resin matrix and had good adhesion with silicone-acrylate resin matrix. Furthermore, the bulge tests were used to investigate the mechanical properties of $\mathrm{rGO} /$ silicone-acrylate resin composite films. The result measured by the bulge tests clearly showed that elastic modulus, yield stress, and adhesive energy of silicone-acrylate resin films were obviously improved by the introduction of rGO. Moreover, the erosion resistance of 


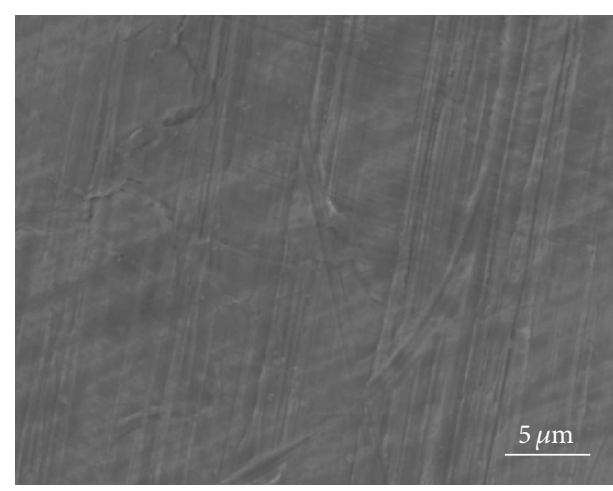

(a)

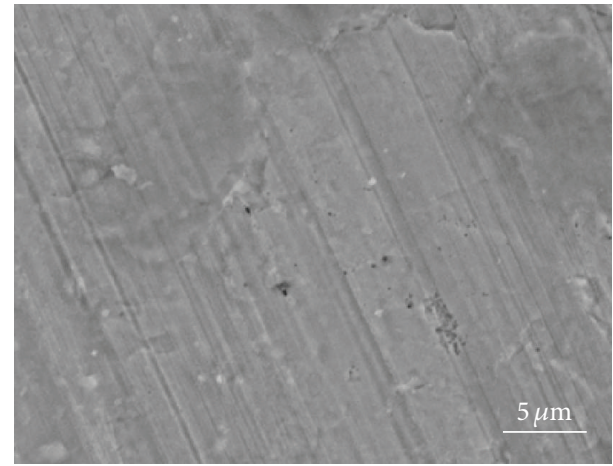

(c)

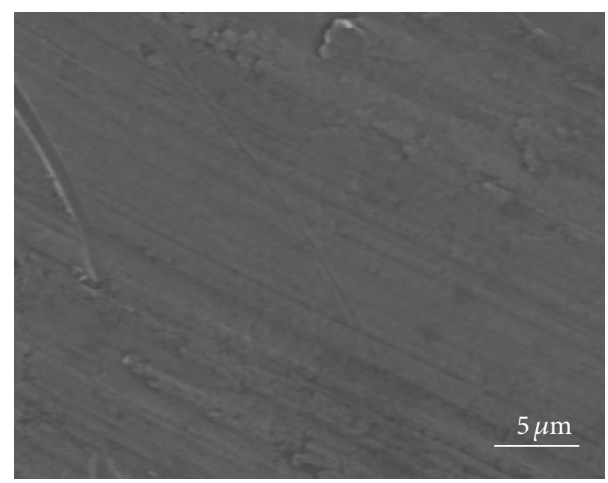

(e)

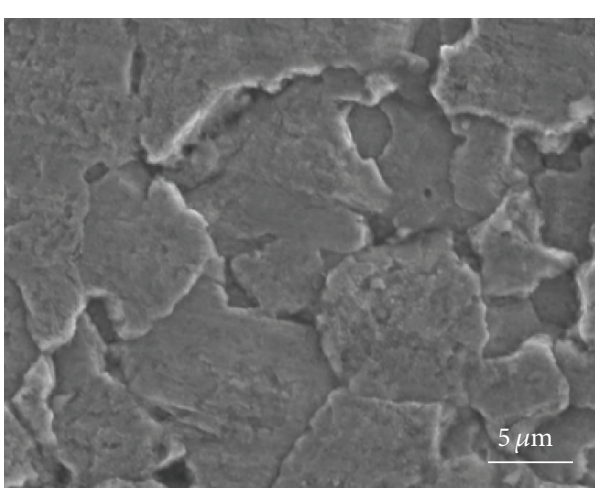

(b)

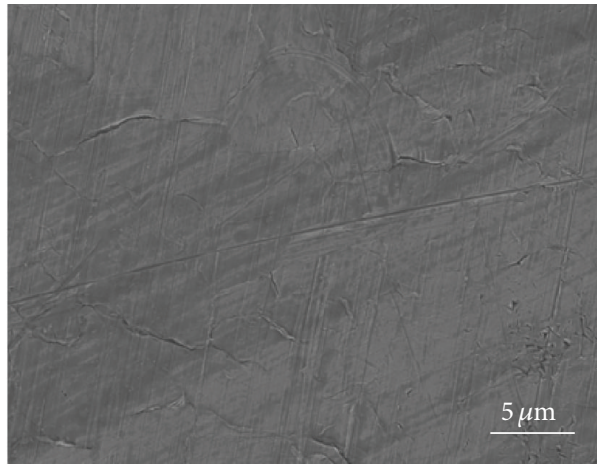

(d)

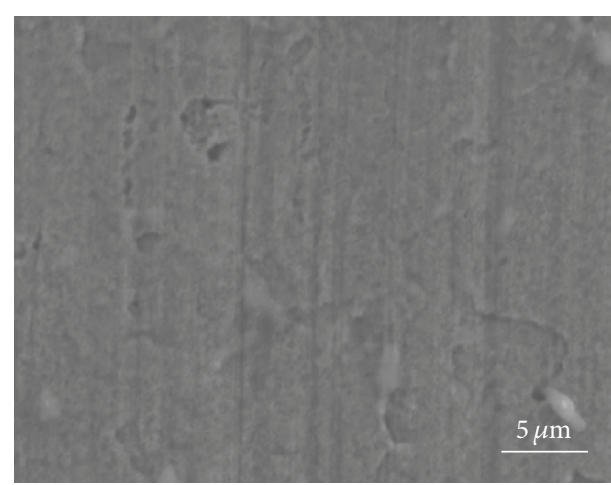

(f)

FIGURE 6: SEM images of uncoated Zn plate (a) before and (b) after corrosion; Zn plate coated polymer composite films with various rGO contents of (c) 0 , (d) $0.27 \mathrm{wt} \%$, (e) $1.1 \mathrm{wt} \%$, and (f) $1.93 \mathrm{wt} \%$.

$\mathrm{rGO} /$ silicone-acrylate resin composite film was also better comparing to the pure silicone-acrylate resin film. These results provide a novel route for studying and improving mechanical properties of $\mathrm{rGO} /$ polymer composite film with good erosion resistance. And the further investigations in erosion resistance of $\mathrm{rGO} /$ silicone-acrylate resin composite film under mechanic-corrosion coupled field have been carried out by our group.

\section{Conflict of Interests}

The authors declare that there is no conflict of interests regarding the publication of this paper.

\section{Acknowledgments}

The authors are grateful for the support by National Natural Science Foundation of China (under Grants 11202006 and 11202007), University's Science and Technology Exploiture of Shanxi Province (20121010), and the Shanxi Provincial Natural Science Foundation of China (2014021018-6).

\section{References}

[1] Corrosion Costs and Preventive Strategies in the United States, 2002, http://isddc.dot.gov/OLPFiles/FHWA/011536.pdf.

[2] C. Yang, W. M. Guo, H. X. Zhang, R. Qiu, J. Hou, and Y. B. Fu, "Study on the corrosion behavior of 7A52 Al alloy welded joint 
by electrochemical method," International Journal of Electrochemical Science, vol. 8, no. 7, pp. 9308-9316, 2013.

[3] A. E. A. Hermas, M. A. Salam, and S. S. Al-Juaid, "In situ electrochemical preparation of multi-walled carbon nanotubes/ polyaniline composite on the stainless steel," Progress in Organic Coatings, vol. 76, no. 12, pp. 1810-1813, 2013.

[4] M. Behpour and N. Mohammadi, "Investigation of inhibition properties of aromatic thiol self-assembled monolayer for corrosion protection," Corrosion Science, vol. 65, pp. 331-339, 2012.

[5] A. B. Chaudhari, A. Anand, S. D. Rajput, R. D. Kulkarni, and V. V. Gite, "Synthesis, characterization and application of Azadirachta indica juss (neem oil) fatty amides (AIJFA) based polyurethanes coatings: a renewable novel approach," Progress in Organic Coatings, vol. 76, no. 12, pp. 1779-1785, 2013.

[6] A. Zomorodian, M. P. Garcia, T. M. E. Silva, J. C. S. Fernandes, M. H. Fernandes, and M. F. Montemor, "Corrosion resistance of a composite polymeric coating applied on biodegradable AZ31 magnesium alloy," Acta Biomaterialia, vol. 9, no. 10, pp. 86608670, 2013.

[7] N. Ostrowski, B. Lee, N. Enick et al., "Corrosion protection and improved cytocompatibility of biodegradable polymeric layerby-layer coatings on AZ31 magnesium alloys," Acta Biomaterialia, vol. 9, no. 10, pp. 8704-8713, 2013.

[8] S. M. Mirabedini and A. Kiamanesh, "The effect of micro and nano-sized particles on mechanical and adhesion properties of a clear polyester powder coating," Progress in Organic Coatings, vol. 76, no. 11, pp. 1625-1632, 2013.

[9] R. Verker, E. Grossman, and N. Eliaz, "Erosion of POSSpolyimide films under hypervelocity impact and atomic oxygen: the role of mechanical properties at elevated temperatures," Acta Materialia, vol. 57, no. 4, pp. 1112-1119, 2009.

[10] Y. Y. Sun, X. Zhou, Y. Q. Liu, G. Z. Zhao, and Y. Jiang, "Effect of magnetic nanoparticles on the properties of magnetic rubber," Materials Research Bulletin, vol. 45, no. 7, pp. 878-881, 2010.

[11] M. M. Shokrieh, M. R. Hosseinkhani, M. R. Naimi-Jamal, and H. Tourani, "Nanoindentation and nanoscratch investigations on graphene-based nanocomposites," Polymer Testing, vol. 32, no. 1, pp. 45-51, 2013.

[12] T. Kanai, T. K. Mahato, and D. Kumar, "Synthesis and characterization of novel silicone acrylate-soya alkyd resin as binder for long life exterior coatings," Progress in Organic Coatings, vol. 58, no. 4, pp. 259-264, 2007.

[13] Y. J. Zhang, H. J. Chi, W. H. Zhang et al., "Highly efficient adsorption of copper ions by a PVP-reduced graphene oxide based on a new adsorptions mechanism," Nano-Micro Letters, vol. 6, no. 1, pp. 80-87, 2014.

[14] C. K. Huang, W. M. Lou, C. J. Tsai, T.-C. Wu, and H.-Y. Lin, "Mechanical properties of polymer thin film measured by the bulge test," Thin Solid Films, vol. 515, no. 18, pp. 7222-7226, 2007.

[15] W. J. Liao, A. J. Gu, G. Z. Liang, and L. Yuan, "New high performance transparent UV-curable poly(methyl methacrylate) grafted $\mathrm{ZnO}$ /silicone-acrylate resin composites with simultaneously improved integrated performance," Colloids and Surfaces A: Physicochemical and Engineering Aspects, vol. 396, pp. 74-82, 2012.

[16] M. K. Small and W. D. Nix, "Analysis of the accuracy of the bulge test in determining the mechanical properties of thin films," Journal of Materials Research, vol. 7, no. 6, pp. 1553-1563, 1992.

[17] H. M. Jensen, "The blister test for interface toughness measurement," Engineering Fracture Mechanics, vol. 40, no. 3, pp. 475486, 1991.
[18] J. M. Yeh, H. Y. Huang, C. L. Chen, W. F. Su, and Y. H. Yu, "Siloxane-modified epoxy resin-clay nanocomposite coatings with advanced anticorrosive properties prepared by a solution dispersion approach," Surface and Coatings Technology, vol. 200, no. 8, pp. 2753-2763, 2006.

[19] S. A. Shojaee, A. Zandiatashbar, N. Koratkar, and D. A. Lucca, "Raman spectroscopic imaging of graphene dispersion in polymer composites," Carbon, vol. 62, pp. 510-513, 2013.

[20] C. F. Matos, F. Galembeck, and A. J. G. Zarbin, "Multifunctional and environmentally friendly nanocomposites between natural rubber and graphene or graphene oxide," Carbon, vol. 78, pp. 469-479, 2014.

[21] S. G. Prolongo, A. Jimenez-Suarez, R. Moriche, and A. Ureña, "In situ processing of epoxy composites reinforced with graphene nanoplatelets," Composites Science and Technology, vol. 86, pp. 185-191, 2013.

[22] Y. Wang, Z. X. Shi, and J. Yin, "Kevlar oligomer functionalized graphene for polymer composites," Polymer, vol. 52, no. 16, pp. 3661-3670, 2011.

[23] M. Cano, U. Khan, T. Sainsbury et al., "Improving the mechanical properties of graphene oxide based materials by covalent attachment of polymer chains," Carbon, vol. 52, pp. 363-371, 2013.

[24] J. Singh-Beemat and J. O. Iroh, "Effect of clay on the corrosion inhibition and dynamic mechanical properties of epoxy esterpolyurea-polysiloxane hybrid coatings," Polymer Engineering \& Science, vol. 52, no. 12, pp. 2611-2619, 2012.

[25] F. Khelifa, M.-E. Druart, Y. Habibi et al., "Sol-gel incorporation of silica nanofillers for tuning the anti-corrosion protection of acrylate-based coatings," Progress in Organic Coatings, vol. 76, no. 5, pp. 900-911, 2013.

[26] D. Prasai, J. C. Tuberquia, R. R. Harl, G. K. Jennings, and K. I. Bolotin, "Graphene: corrosion-inhibiting coating," ACS Nano, vol. 6, no. 2, pp. 1102-1108, 2012.

[27] P. K. Nayak, C.-J. Hsu, S.-C. Wang, J. C. Sung, and J.-L. Huang, "Graphene coated Ni films: a protective coating," Thin Solid Films, vol. 529, pp. 312-316, 2013.

[28] W. Zhang, M. Yi, Z. G. Shen, X. H. Zhao, X. J. Zhang, and S. L. $\mathrm{Ma}$, "Graphene-reinforced epoxy resin with enhanced atomic oxygen erosion resistance," Journal of Materials Science, vol. 48, no. 6, pp. 2416-2423, 2013. 

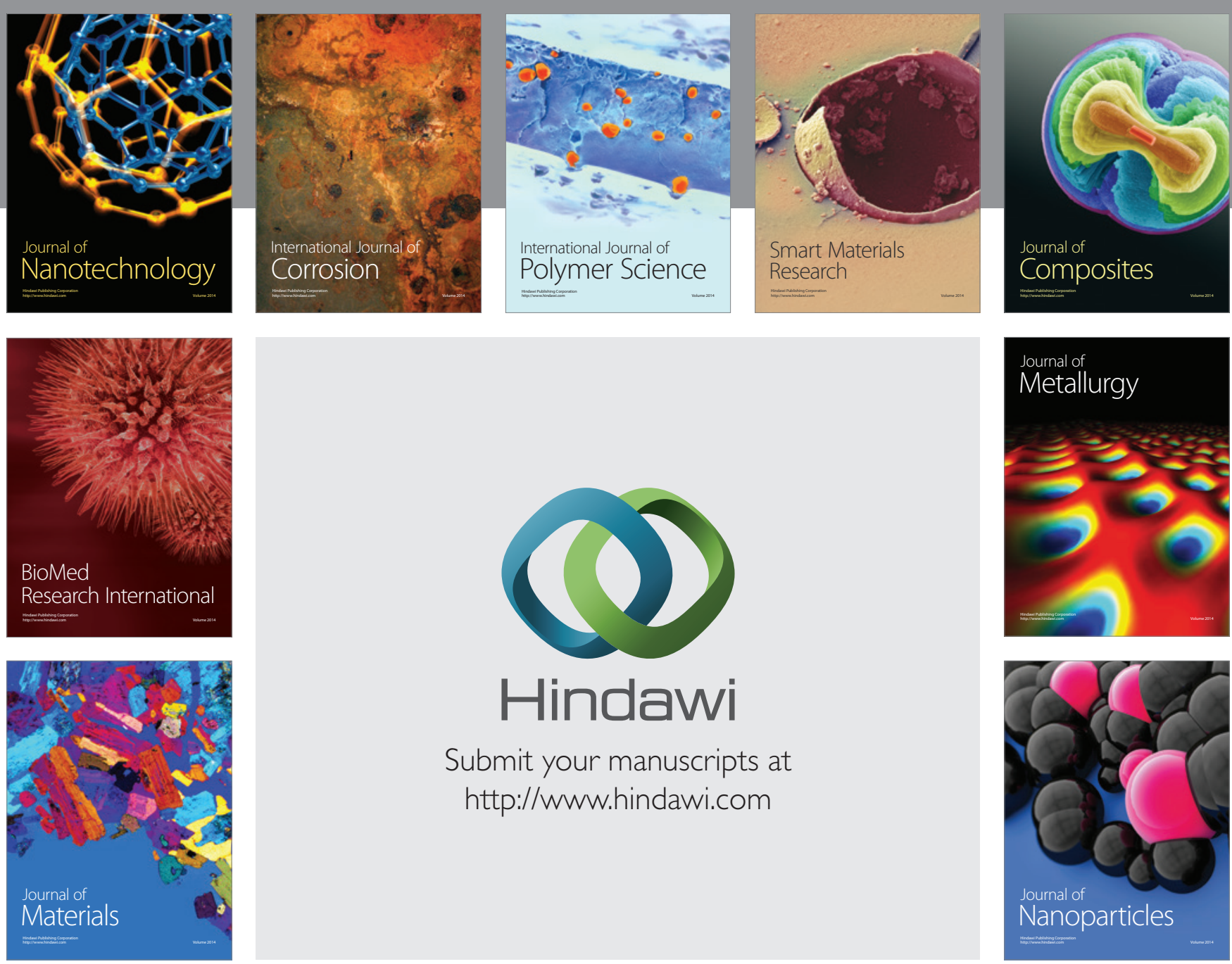

Submit your manuscripts at http://www.hindawi.com
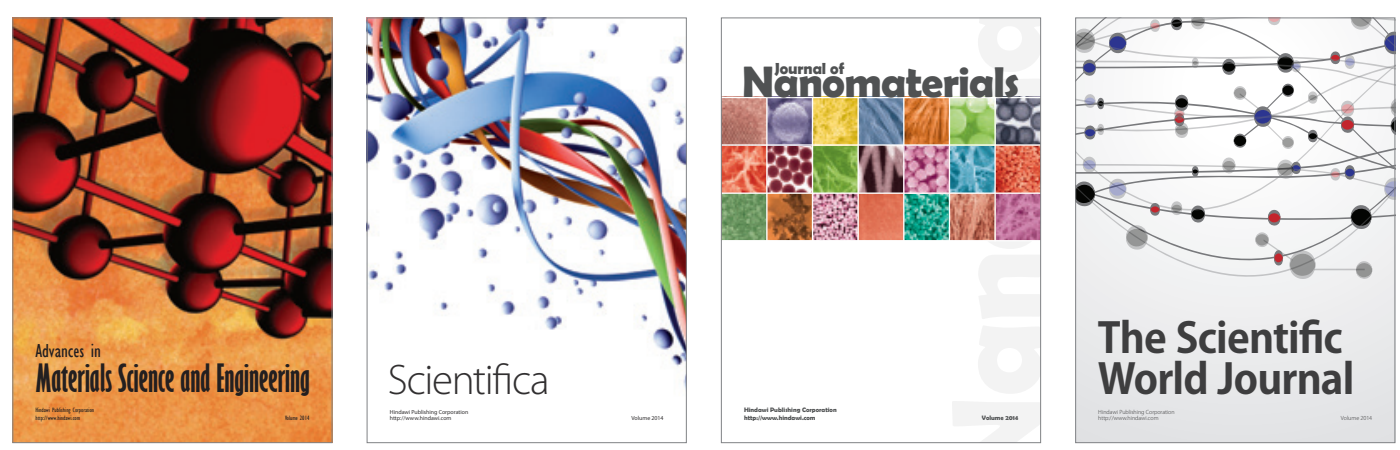

\section{The Scientific World Journal}
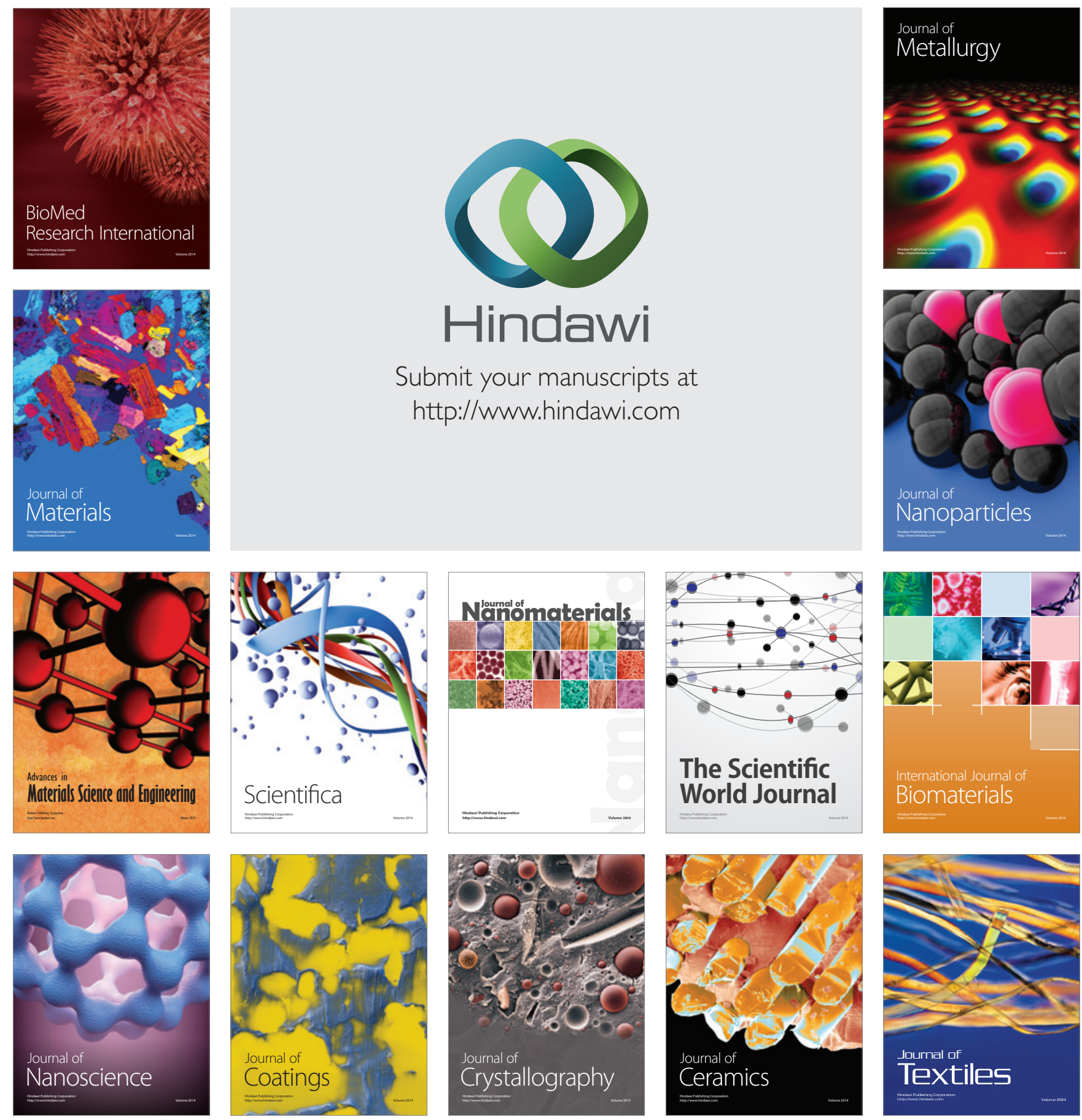